\title{
Identification of membrane-bound quinoprotein inositol dehydrogenase in Gluconobacter oxydans ATCC $621 \mathrm{H}$
}

\author{
Tina Hölscher, Dinusha Weinert-Sepalage and Helmut Görisch \\ Fachgebiet Technische Biochemie, Institut für Biotechnologie, Technische Universität Berlin, \\ D-13353 Berlin, Germany
}

Correspondence

Tina Hölscher

Tina.Hoelscher@TU-berlin.de

Received 5 September 2006

Revised 3 November 2006

Accepted 7 November 2006

\begin{abstract}
The GOX1857 gene, which encodes a putative membrane-bound pyrroloquinoline quinone (PQQ)-dependent dehydrogenase in Gluconobacter oxydans ATCC $621 \mathrm{H}$, was characterized. GOX1857 was disrupted and the oxidizing potential of the resulting mutant strain was compared to that of the wild-type. In contrast to the wild-type, the mutant was unable to grow with myo-inositol as the sole energy source and did not show any myo-inositol dehydrogenase activity in vitro, indicating that GOX1857 encodes an inositol dehydrogenase. The association of inositol dehydrogenase with the membrane and the requirement for the cofactor PQQ were confirmed. Inositol dehydrogenase exhibited optimal activity at $\mathrm{pH}$ 8.75. As indicated by cultivation on different substrates, inositol dehydrogenase was repressed by D-glucose.
\end{abstract}

\section{INTRODUCTION}

The acetic acid bacterium Gluconobacter oxydans is characterized by its ability to incompletely oxidize various sugars, alcohols and polyols in the periplasm (Matsushita et al., 1994). Substrates are oxidized stereo- and regioselectively and the resulting aldehydes, ketones and organic acids are excreted into the medium. G. oxydans is used in several industrial processes; e.g. in the production of L-sorbose, an intermediate in the synthesis of vitamin C (reviewed by Bremus et al., 2006). The key oxidation reactions in these processes are catalysed by membraneassociated dehydrogenases that are part of the respiratory chain (Matsushita et al., 1994; Goodwin \& Anthony, 1998) and often contain pyrroloquinoline quinone (PQQ) as cofactor. Several PQQ-dependent dehydrogenases of $G$. oxydans have been identified and characterized: the quinoprotein glucose dehydrogenase (Ameyama et al., 1981), the quinoprotein glycerol dehydrogenase, which also oxidizes D-gluconate, D-mannitol and other polyols (Matsushita et al., 2003), and the quinohaemoprotein alcohol dehydrogenase (Matsushita et al., 1994). In G. oxydans strain IFO3244, a quinoprotein quinate dehydrogenase has been detected (Vangnai et al., 2004). During growth of G. oxydans in complex medium supplied with sugars, incomplete oxidation of sugars by the membrane-bound dehydrogenases provides energy for growth, while the carbon for growth can be obtained from both the sugar and the complex components, i.e. yeast extract or tryptone. Channelling of sugars into the biosynthetic pathways is

Abbreviations: DCPIP, 2,6-dichlorophenol indophenol; PMS, phenazine methosulphate; $\mathrm{PQQ}$, pyrroloquinoline quinone. mediated by cytosolic $\mathrm{NAD}(\mathrm{P})$-dependent dehydrogenases (Matsushita et al., 1994).

Although several oxidation reactions and the enzymes involved have been described, the oxidation potential of Gluconobacter strains has not yet been fully elucidated. Recently, the complete genome of G. oxydans ATCC $621 \mathrm{H}$ (DSM 2343) has been sequenced (Prust et al., 2005), revealing the presence of 75 uncharacterized dehydrogenases, 23 of which are predicted to be membrane-bound. Three of these membrane-bound dehydrogenases share high homology with known quinoproteins, while others belong to flavin-containing enzyme families (Prust et al., 2005). In this study, we investigated the GOX1857 gene, which encodes one of the putative membrane-bound quinoprotein dehydrogenases in G. oxydans ATCC $621 \mathrm{H}$. To characterize the catalytic activity of the encoded enzyme, GOX1857 was disrupted and properties of the mutant were compared to those of the wild-type strain.

\section{METHODS}

Bacterial strains and culture conditions. The relevant characteristics and references for the strains and plasmids used in this work are listed in Table 1. Escherichia coli strains were grown in Luria-Bertani medium (Sambrook et al., 1989). G. oxydans ATCC $621 \mathrm{H}$ was routinely grown in complex medium containing $0.5 \%$ yeast extract and $0.3 \%$ tryptone, $\mathrm{pH} 6.0$, supplemented with $250 \mathrm{mM}$ D-mannitol (mannitol medium). Growth was recorded by measurement of the optical density at $620 \mathrm{~nm}\left(\mathrm{OD}_{620}\right)$. When appropriate, D-mannitol was replaced by D-sorbitol, D-glucose or myo-inositol. When D-glucose was used, potassium succinate (100 mM) was added as a buffering agent. For growth screening, cells pre-grown in mannitol medium and pelleted at $3000 \mathrm{~g}$ for $15 \mathrm{~min}$ were used. Growth tests were carried out in complex 
Table 1. Strains and plasmids

\begin{tabular}{|c|c|c|}
\hline Strain or plasmid & Characteristics & Reference \\
\hline \multicolumn{3}{|l|}{ Strains } \\
\hline $\begin{array}{l}\text { G. oxydans ATCC } 621 \mathrm{H} \\
\text { (DSM 2343) }\end{array}$ & Wild-type strain & Gillis \& de Ley (1980) \\
\hline G. oxydans DW1 & ATCC $621 \mathrm{H}$ derivative, $\mathrm{Gm}^{\mathrm{R}}$ inserted in GOX1857 gene & This study \\
\hline G. oxydans $\mathrm{TH} 1$ & ATCC $621 \mathrm{H}$ derivative, $p q q A:: \mathrm{Km}^{\mathrm{R}}$ & Hölscher \& Görisch (2006) \\
\hline E. coli $\mathrm{DH} 5 \alpha$ & $\begin{array}{l}\text { supE44 } \Delta \text { lacU169 ( } \phi 80 \text { lacZAM15) hsdR17 recA1 endA1 } \\
\text { gyrA96 thi-1 relA1 }\end{array}$ & Hanahan (1983) \\
\hline E. coli $\mathrm{HB} 101$ & $\begin{array}{l}\text { supE44 hsdS20 }\left(\mathrm{r}_{\mathrm{B}}^{-} \mathrm{m}_{\mathrm{B}}^{-}\right) \text {recA13 ara-14 proA2 lacY1 galK2 } \\
\text { rpsL20 xyl-5 mtl-1 }\end{array}$ & Boyer \& Roulland-Dussoix (1969) \\
\hline \multicolumn{3}{|l|}{ Plasmids } \\
\hline pBBR1MCS-2 & Broad-host-range cloning vector, $\mathrm{Km}^{\mathrm{R}}$ & Kovach et al. (1995) \\
\hline pRK2013 & Helper plasmid for triparental mating, $\mathrm{Km}^{\mathrm{R}}$ & Figurski \& Helinski (1979) \\
\hline pKmob18GII & Gene replacement vector, gus $A, \mathrm{Km}^{\mathrm{R}}$ & Katzen et al. (1999) \\
\hline pTB9042 & $\begin{array}{l}\text { pKmobGII derivative containing an internal fragment of } \\
\text { GOX1857, } \mathrm{Km}^{\mathrm{R}}\end{array}$ & This study \\
\hline рТВ9049 & $\begin{array}{l}\text { pKmobGII derivative containing an internal fragment of } \\
\text { GOX1857 disrupted by the } \mathrm{Gm}^{\mathrm{R}} \text { gene, } \mathrm{Km}^{\mathrm{R}} \mathrm{Gm}^{\mathrm{R}}\end{array}$ & This study \\
\hline pTB9058 & $\begin{array}{l}\text { pBBR1MCS-2 derivative containing the complete } \\
\text { GOX1857 gene including its putative promoter region, } \mathrm{Km}^{\mathrm{R}}\end{array}$ & This study \\
\hline
\end{tabular}

medium containing various substrates at a concentration of $20 \mathrm{mM}$. Antibiotics were used at the following concentrations: kanamycin, $50 \mu \mathrm{g} \mathrm{ml}^{-1}$, gentamicin, $10 \mu \mathrm{g} \mathrm{ml}^{-1}$ (E. coli) or $50 \mu \mathrm{g} \mathrm{ml}^{-1}$ (G. oxydans), cefoxitin, $50 \mu \mathrm{g} \mathrm{ml}^{-1}$.

General genetic techniques. DNA work was performed according to standard protocols (Ausubel et al., 2002; Sambrook et al., 1989). For PCR reactions, genomic DNA isolated from G. oxydans ATCC $621 \mathrm{H}$ was used as the template. Pfu DNA polymerase (Promega Biosciences) was used for PCR-amplification of inserts for cloning, and Taq DNA polymerase (Rapidozym) was used for PCR amplification in test reactions (e.g. colony PCR).

Vector construction. To generate a gene replacement vector for inactivation of GOX1857 in G. oxydans ATCC $621 \mathrm{H}$, a $1.47 \mathrm{~kb}$ internal fragment of GOX1857 was amplified with forward primer 5'-GGAATTCAACCGCGACAATGTCGGCAAG-3' (restriction site underlined) and reverse primer 5'-GCGAAGCTTCGGCATGCTCCATTTCACCTTG- $3^{\prime}$ and cloned between the EcoRI and HindIII sites of pKmob18GII, resulting in plasmid pTB9042. The GOX1857 fragment within pTB9042 was interrupted by insertion of the gentamicin resistance cassette of vector pBBR1MCS-5 between the NotI and AatII sites, resulting in plasmid pTB9049.

For mutant complementation, a $2.65 \mathrm{~kb}$ fragment containing the complete GOX1857 gene including its putative promoter region was amplified with forward primer 5'-GGAATTCGAAATCTTCTGATCGCTCCAG-3' and reverse primer 5'-TGCAAGCTTCTGCGCTCTTATTCTTCGGAG- $3^{\prime}$ and cloned between the EcoRI and HindIII sites of plasmid pBBR1MCS-2, resulting in plasmid pTB9058.

Conjugational plasmid transfer into G. oxydans. Plasmids were transferred into $G$. oxydans by triparental mating using E. coli DH5 $\alpha$ bearing the respective vector as the donor and E. coli HB101 bearing plasmid pRK2013 as the helper strain. The three strains were grown to late exponential phase, pelleted, resuspended in mannitol medium and mixed in a 1:1:1 ratio. The mixture was plated on mannitol medium agar and incubated overnight at $30^{\circ} \mathrm{C}$. The resulting cell patches were scraped from the plates and streaked on selective mannitol medium agar containing cefoxitin and the appropriate selective antibiotic (kanamycin or gentamicin). Plates were incubated for 2-4 days until kanamycin/gentamicin-resistant colonies appeared.

Preparation of crude extracts and membrane fractions. $G$. oxydans was grown in complex medium containing different carbon sources to late exponential phase $\left(\mathrm{OD}_{620} 0.9\right)$. Cells were harvested by centrifugation at $5000 \mathrm{~g}$ for $10 \mathrm{~min}$, washed once with $10 \mathrm{mM}$ Tris/ $\mathrm{HCl}$ buffer, $\mathrm{pH} 7$, and resuspended in the same buffer. Cells were broken by three cycles of ultrasonication using a Branson sonifier 250 (intensity 4, $20 \%$ duty cycle, $5 \mathrm{~min}$ ). The supernatant obtained after centrifugation of broken cells at $10000 \mathrm{~g}$ for $10 \mathrm{~min}$ was used as the crude extract. The crude extract was centrifuged at $100000 \mathrm{~g}$ for $60 \mathrm{~min}$ and the pellet was washed once with $10 \mathrm{mM}$ Tris/ $\mathrm{HCl}$ buffer, $\mathrm{pH} 7$, resuspended in the same buffer and used as the membrane fraction.

Dehydrogenase assay. Dehydrogenase activity was determined photometrically at $25^{\circ} \mathrm{C}$ in a dye-linked system containing 2,6dichlorophenol indophenol (DCPIP) and phenazine methosulphate (PMS). The reaction mixture contained enzyme solution, buffer (see below), $33 \mathrm{mM}$ substrate, $0.67 \mathrm{mM}$ PMS, $0.1 \mathrm{mM}$ DCPIP and $4 \mathrm{mM}$ sodium azide. One unit of dehydrogenase activity was defined as the reduction of $1 \mu \mathrm{mol}$ DCPIP per min, corresponding to the oxidation of $1 \mu \mathrm{mol}$ substrate per min. Inositol dehydrogenase activity was routinely measured at $600 \mathrm{~nm}$ in $167 \mathrm{mM}$ Tris/HCl, $\mathrm{pH} 8.75$ $\left(\varepsilon_{\text {DCPIP }}=23 \mathrm{mM}^{-1} \mathrm{~cm}^{-1}\right)$. Dehydrogenase activities with ethanol, D-gluconate, glycerol, D-mannitol and D-sorbitol were measured at $520 \mathrm{~nm}$ in Mcllvaine buffer at pH $5.0\left(\varepsilon_{\text {DCPIP }}=10.5 \mathrm{mM}^{-1} \mathrm{~cm}^{-1}\right)$. Glucose dehydrogenase activity was measured at $600 \mathrm{~nm}$ in McIlvaine buffer at pH $6.0\left(\varepsilon_{\text {DCPIP }}=17.2 \mathrm{mM}^{-1} \mathrm{~cm}^{-1}\right)$. For preparation of apoenzymes, samples were incubated with $10 \mathrm{mM}$ EDTA for $60 \mathrm{~min}$ at $30^{\circ} \mathrm{C}$. For reconstitution of quinoprotein apoenzymes to the holoenzymes, samples were incubated with $16.5 \mu \mathrm{M}$ PQQ and $20 \mathrm{mM} \mathrm{MgSO}_{4}$ or $20 \mathrm{mM} \mathrm{CaCl}_{2}$ for $10 \mathrm{~min}$ at $25^{\circ} \mathrm{C}$, without prior removal of EDTA. The PQQ-deficient G. oxydans mutant TH1 only produces quinoprotein apoenzymes 
(Hölscher \& Görisch, 2006) so EDTA treatment was not necessary. Here, samples were incubated with $16.5 \mu \mathrm{M}$ PQQ and $10 \mathrm{mM}$ $\mathrm{MgSO}_{4}$ to obtain quinoprotein holoenzymes.

Sequence analysis. The sequence of the GOX1857 gene of G. oxydans ATCC $621 \mathrm{H}$ was obtained from the NCBI web site (http:// www.ncbi.nlm.nih.gov; accession number YP_192251). The predicted amino acid sequence of GOX1857 was compared to other published sequences using the National Center for Biotechnology Information BLASTP search tool (http://www.ncbi.nlm.nih.gov/blast/). Sequences were aligned with the CLUSTALW program located at the European Bioinformatics Institute website (http://www.ebi.ac.uk/ clustalw/). Analysis of the putative promoter region of GOX1857 was carried out with the Neural Network Promoter Prediction tool (http://www.fruitfly.org/seq_tools/promoter.html), and transmembrane helices in proteins were predicted with the TMHMM tool located at the Center for Biological Sequence Analysis website (http://www.cbs.dtu.dk/services/TMHMM-2.0/).

\section{RESULTS}

\section{Generation of a mutant with a defective GOX1857 gene}

GOX1857 was disrupted in G. oxydans ATCC $621 \mathrm{H}$ using the gene replacement vector pKmob18GII, which contains the gusA marker (Katzen et al., 1999). Since pKmob18GII carries a kanamycin resistance gene, a gentamicin cassette was used for gene inactivation. Double-crossover mutants were identified by blue/white screening as described previously (Katzen et al., 1999; Hölscher \& Görisch, 2006); blue colonies could be observed 2 days after plating. A colourless, kanamycin-sensitive colony representing a double-crossover mutant (GOX1857:: $\mathrm{Gm}^{\mathrm{R}}$ ) was isolated and named DW1. The disruption of GOX1857 by the gentamicin cassette and the absence of the vector within the genome of DW1 were confirmed by PCR.

\section{Growth of G. oxydans wild-type and mutant DW1 with different substrates}

Growth of G. oxydans wild-type and mutant DW1 was tested in complex medium containing $20 \mathrm{mM}$ of one of the following substrates: meso-erythritol, ethanol, D-fructose, D-fucose, D-gluconate, D-glucose, glycerol, myo-inositol, maltose, D-mannitol, ribitol, D-ribose, D-sorbitol, L-sorbose, sucrose and xylitol. Cultures were started with an $\mathrm{OD}_{620}$ of 0.05 . With all substrates tested except myo-inositol, no significant difference in growth was observed between the wild-type strain and mutant DW1 in two independent experiments. Both strains grew to final optical densities varying between 0.2 and 1 with meso-erythritol, D-fructose, D-gluconate, D-glucose, glycerol, D-mannitol and D-sorbitol. Poor growth, limited to a maximum $\mathrm{OD}_{620}$ of 0.1 , was found with ethanol, xylitol, ribitol and L-sorbose. No growth was found with D-fucose, D-ribose, sucrose and maltose or with no added substrate. With myo-inositol $(1,2,3,5 / 4,6$-cyclohexanehexol), the wild-type grew to a final $\mathrm{OD}_{620}$ of 0.15 , whereas mutant DW1 did not grow at all. Therefore, it was concluded that DW1 had a defective inositol dehydrogenase. However, growth of G. oxydans wild-type with $20 \mathrm{mM}$ myo-inositol in liquid culture was rather poor. Also, cultivation with myo-inositol concentrations of $100-500 \mathrm{mM}$ did not result in higher final cell densities. On complex medium agar containing myoinositol (100 mM), the wild-type strain grew slowly; small colonies appeared 2-3 days after plating. No growth was found for mutant DW1 on the same agar.

\section{Dehydrogenase activities in wild-type and mutant DW1 with different substrates}

Dye-linked dehydrogenase activities with different substrates were assayed in crude extracts of G. oxydans wild-type and mutant DW1 grown in complex medium containing $250 \mathrm{mM}$ D-sorbitol. With ethanol, D-gluconate, D-glucose, glycerol, D-mannitol and D-sorbitol as substrate, both strains exhibited similar dehydrogenase activities (data not shown). No dye-linked dehydrogenase activity was found in either the wild-type or DW1 with quinate or shikimate as substrate. In contrast, with myo-inositol, dehydrogenase activity was present in crude extracts of the wild-type but was absent in DW1 extracts (Table 2). The effect of the growth substrate on myo-inositol dehydrogenase activity in the wild-type, as shown in Table 2, is discussed below.

\section{Properties of inositol dehydrogenase}

Dye-linked myo-inositol dehydrogenase in crude extracts of G. oxydans exhibited optimal activity at $\mathrm{pH} 8.75$ in Tris/HCl buffer. Activity was nearly absent below pH 5 (Mcllvaine buffer) and above pH 10.5 (CAPS buffer). Therefore, all further measurements were carried out at $\mathrm{pH}$ 8.75. The apparent $K_{\mathrm{m}}$ value for oxidation of myo-inositol in crude extracts using the DCPIP-PMS assay was $5 \mathrm{mM}$. Maximal activity was already obtained at $33 \mathrm{mM}$ myo-inositol; higher myo-inositol concentrations even led to a slight decrease in dehydrogenase activity. In crude extracts from cells grown on D-sorbitol, maximal specific activity amounted to about $90 \mathrm{mU}$ per mg protein. Crude extracts of the wild-type, but not of mutant DW1, also oxidized allo-inositol $(1,2,3,4$ / 5,6-cyclohexanehexol) and muco-inositol (1,2,4,5/3,6cyclohexanehexol). The apparent $K_{\mathrm{m}}$ values for allo- and muco-inositol (10-15 $\mathrm{mM})$ were slightly higher than that for myo-inositol. Maximal specific activities were obtained at $60-70 \mathrm{mM}$ allo-inositol and $33 \mathrm{mM}$ muco-inositol and corresponded to $160 \%$ and $67 \%$ of the specific activity with myo-inositol, respectively. Again, higher inositol concentrations slightly inhibited dehydrogenase activity.

The major portion of dye-linked myo-inositol dehydrogenase activity was membrane-associated and amounted to $600 \mathrm{mU}$ per mg membrane protein. In the fraction containing soluble proteins, a specific activity of only $30 \mathrm{mU}$ was found. Activity of PQQ-dependent enzymes requires the presence of divalent metal ions such as $\mathrm{Ca}^{2+}$ or $\mathrm{Mg}^{2+}$, which are coordinated to the PQQ in the active site (Goodwin \& Anthony, 1998). In membranes of the G. oxydans mutant $\mathrm{TH} 1$, which is unable to synthesize PQQ (Hölscher \& Görisch, 2006), myo-inositol dehydrogenase 
Table 2. Dye-linked myo-inositol dehydrogenase activities in crude extracts of $G$. oxydans wild-type and GOX1857:: Gm ${ }^{\mathrm{R}}$ mutant DW1 after growth on different substrates

\begin{tabular}{|c|c|c|}
\hline \multirow[t]{2}{*}{ Growth substrate } & \multicolumn{2}{|c|}{ Specific myo-inositol dehydrogenase activity $\left[\mathrm{mU}(\mathrm{mg} \text { protein })^{-1}\right]^{\star}$} \\
\hline & Wild-type & Mutant DW1 \\
\hline D-Sorbitol & $94 \pm 16$ & $<5 \ddagger$ \\
\hline D-Mannitol & $24 \pm 2$ & $<5$ \\
\hline D-Glucose & $<5$ & $<5$ \\
\hline D-Sorbitol + myo-inositol & $87 \dagger$ & $<5$ \\
\hline D-Mannitol + myo-inositol & $27 \dagger$ & ND \\
\hline D-Glucose + myo-inositol & $<5$ & ND \\
\hline D-Sorbitol, $\mathrm{OD}_{620} 0.15 \S$ & $39 \dagger$ & ND \\
\hline myo-Inositol, $\mathrm{OD}_{620} 0.15 \S$ & $214 \dagger$ & NG \\
\hline
\end{tabular}

ND, Not determined; NG, no growth under these conditions.

${ }^{*}$ Means \pm SD of results of independent triplicate growth tests.

$\dagger$ Means of results of independent duplicate growth tests.

$\ddagger m y o$-Inositol dehydrogenase activity found in crude extracts of the complemented mutant DW1-pTB9058

was $75 \mathrm{mU} \mathrm{mg}^{-1}$.

$\S$ Strains were harvested at an optical density of 0.15 (see text for details).

activity was absent, but could be restored by addition of PQQ and $\mathrm{Mg}^{2+}$. Furthermore, treatment of wild-type crude extracts with $10 \mathrm{mM}$ EDTA completely inactivated inositol dehydrogenase. Without prior removal of EDTA, activity was restored by addition of PQQ and $20 \mathrm{mM} \mathrm{Mg}^{2+}$ or $\mathrm{Ca}^{2+}$.

\section{Inositol dehydrogenase activity after growth on different substrates}

To study the effect of different growth substrates on inositol dehydrogenase activity, G. oxydans wild-type was routinely grown to an $\mathrm{OD}_{620}$ of 0.9. After growth on D-sorbitol, dyelinked myo-inositol dehydrogenase activity in crude extracts amounted to about $94 \mathrm{mU}$ per $\mathrm{mg}$ protein (Table 2). A similar specific activity was obtained when cultivation was carried out with a mixture of D-sorbitol $(250 \mathrm{mM})$ and myo-inositol $(100 \mathrm{mM})$. After growth on D-mannitol $(250 \mathrm{mM})$ or a mixture of D-mannitol and myo-inositol, myo-inositol dehydrogenase activity reached only about $27 \%$ of the activity of sorbitol-grown cells. When D-glucose $(250 \mathrm{mM})$ or a mixture of D-glucose and myo-inositol were used for cultivation, myo-inositol dehydrogenase activity was negligible (Table 2). With myo-inositol as sole substrate $(100 \mathrm{mM})$, growth of the wild-type was restricted to a final $\mathrm{OD}_{620}$ of 0.15 (see above). Using myo-inositol-grown cells, specific myo-inositol dehydrogenase activity in crude extracts was about twofold higher than after growth on D-sorbitol to an $\mathrm{OD}_{620}$ of 0.9 and about fivefold higher than after growth on D-sorbitol to an $\mathrm{OD}_{620}$ of 0.15 . Under the cultivation conditions tested, i.e. with D-sorbitol, D-mannitol, D-glucose or a mixture of D-sorbitol and myo-inositol, dye-linked myo-inositol dehydrogenase activity was not detected in crude extracts of mutant DW1 (Table 2).

\section{Complementation of mutant DW1}

Mutant DW1 could be complemented by plasmid pTB9058, which contained the GOX1857 gene including its own putative promoter region. As with the wild-type strain, mutant DW1 bearing pTB9058 grew with myo-inositol in liquid culture and on agar. Crude extracts of the complemented mutant oxidized myo-, allo- and muco-inositol.

\section{Gene GOX1857 and the amino acid sequence of quinoprotein inositol dehydrogenase}

DNA sequence analysis suggested that GOX1857 is organized in a monocistronic operon. The region upstream of GOX1857 most probably represents a promoter (promoter prediction score of 0.98 ). The open reading frame consists of $2367 \mathrm{bp}$ encoding a putative $85.4 \mathrm{kDa}$ protein. A BLASTP search and pairwise alignments using CLUSTALW revealed that the quinoprotein inositol dehydrogenase encoded by GOX1857 showed the highest sequence identity to the putative quinoprotein quinate dehydrogenase from Pseudomonas fluorescens Pf-5 (46.7\%; accession number YP_262726) and the putative quinoprotein glucose dehydrogenase from Pseudomonas syringae (46\%; accession number AAO56073). Maximal sequence identity with biochemically characterized proteins was found with the quinoprotein quinate dehydrogenase from Acinetobacter sp. ADP1 (40.7\%; accession number Q59086) and the quinoprotein glucose dehydrogenase from E. coli (37.7\%; accession number P15877) (Fig. 1). The predicted topology of quinoprotein inositol dehydrogenase is similar to that of the well-studied E. coli quinoprotein glucose dehydrogenase, which is made up of five $\mathrm{N}$-terminal transmembrane helices and a catalytic C-terminal domain facing the periplasm (Yamada et al., 1993). Regions with similarity to the tryptophan docking motifs of the so-called 


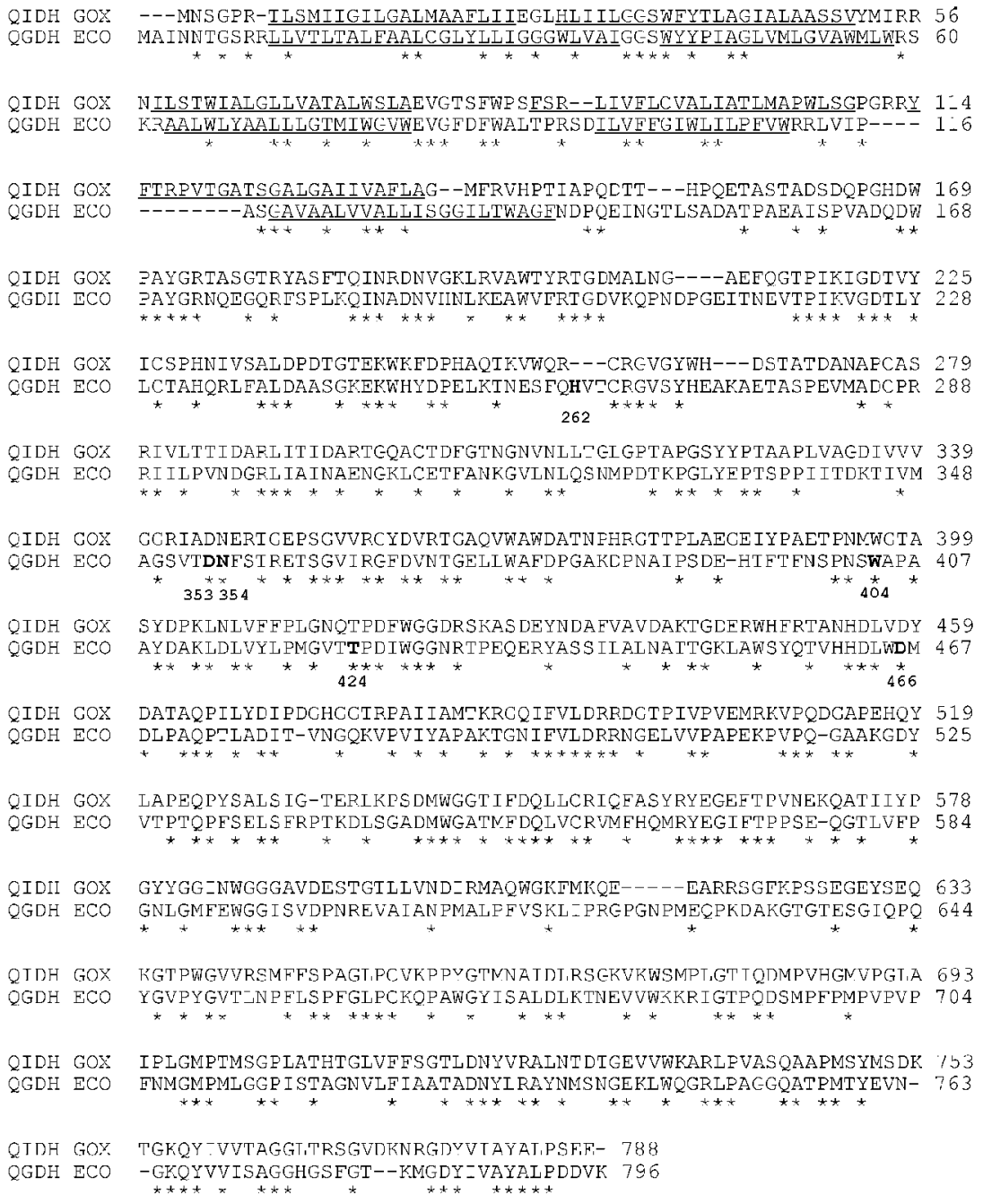

Fig. 1. Alignment of the amino acid sequences of G. oxydans quinoprotein inositol dehydrogenase (QIDH GOX) and E. coli quinoprotein glucose dehydrogenase (QGDH ECO). The asterisks denote identical residues in both sequences. Regions of transmembrane helices determined for the glucose dehydrogenase (Yamada et al., 1993) and predicted for the inositol dehydrogenase are underlined. Functionally important residues located in the active site of glucose dehydrogenase are numbered and in bold.

'propeller fold', the common structure of PQQ-dependent dehydrogenases (Goodwin \& Anthony, 1998; Toyama et al., 2004), were also found in the inositol dehydrogenase (not shown). As revealed by the resolved X-ray structures of several alcohol dehydrogenases, the PQQ molecule is supported by a Trp or Phe residue, which corresponds to Trp-404 in the modelled structure of the E. coli glucose dehydrogenase (Cozier \& Anthony, 1995). A Trp residue was also found in the respective region of inositol dehydrogenase (Fig. 1). In alcohol dehydrogenases, the PQQ molecule is covered by an unusual bis-cysteine ring made up of two adjacent cysteines, which is replaced by a histidine (His-262) in the model glucose dehydrogenase (Fig. 1). This histidine residue is also required for high affinity to glucose (Cozier et al., 1999). Inositol dehydrogenase contains neither two adjacent cysteines nor a histidine residue at the corresponding site. However, the enzyme shares the conserved Asp residue present in all studied PQQdependent dehydrogenases, which is believed to initiate the catalytic reaction and corresponds to Asp-466 in the E. coli glucose dehydrogenase. Furthermore, inositol dehydrogenase shares the conserved Asp, Asn and Thr residues of glucose dehydrogenases (Asp-353, Asn-354, Thr-424; Fig. 1), which most probably interact with the metal ion in the active site (Cozier \& Anthony, 1995).

\section{DISCUSSION}

To characterize GOX1857, encoding a putative PQQdependent dehydrogenase in G. oxydans, we generated a mutant with a defective GOX1857 gene. Growth screening and dehydrogenase assays with a selection of sugars and 
sugar alcohols revealed that only with myo-inositol and other inositols as substrates did the GOX1857 knockout mutant DW1 differ from the wild-type. Whereas the wildtype grew, albeit slowly, on myo-inositol and oxidized myoinositol in vitro, no growth and no dehydrogenase activity were found for DW1 with this substrate. Therefore, we concluded that GOX1857 encodes an inositol dehydrogenase.

Dye-linked inositol dehydrogenase activity was associated with the membrane of $G$. oxydans wild-type. In a PQQdeficient G. oxydans mutant (Hölscher \& Görisch, 2006) or after treatment of wild-type crude extracts with a chelating agent, a procedure that converts quinoproteins into the apoform (Mutzel \& Görisch, 1991; Adachi et al., 2001), inositol dehydrogenase activity was absent. These results confirmed that the enzyme is a membrane-bound quinoprotein, as had previously been concluded from sequence analysis of the encoding gene (Prust et al., 2005). In G. oxydans, membrane-bound quinoproteins are involved in energy generation by mediating incomplete oxidation (Matsushita et al., 1994). Therefore, we assume that quinoprotein inositol dehydrogenase is required for growth of G. oxydans with myo-inositol as sole energy source.

Expression of inositol dehydrogenase is regulated. Our results demonstrate that different specific activities of inositol dehydrogenase are obtained in cultures grown on different substrates. Using chip-based genome-wide transcription analysis, GOX1857 had previously been shown to be highly expressed upon growth on D-sorbitol and D-mannitol, but not upon growth on D-glucose (M. Hoffmeister \& A. Ehrenreich, personal communication). Consistently, in our study, inositol dehydrogenase activity was found after growth with D-sorbitol and, to a lesser extent, with D-mannitol, but not after growth with D-glucose. When D-sorbitol, D-mannitol or D-glucose were used in combination with myo-inositol in the growth medium, the respective inositol dehydrogenase activities were not altered, although the highest inositol dehydrogenase activity was indeed obtained after growth on myoinositol alone. The lack of activity after growth on D-glucose or a mixture of myo-inositol and D-glucose suggests that inositol dehydrogenase is subject to catabolite repression by D-glucose. As described above, reduced activities were also obtained after cultivation with mixtures of myo-inositol and D-mannitol or myo-inositol and D-sorbitol. The reasons for the regulatory effects of D-sorbitol and D-mannitol on expression of inositol dehydrogenase are not understood at present.

To our knowledge, this is the first identification of a gene encoding a membrane-bound inositol dehydrogenase. In early biochemical studies, myo-inositol dehydrogenase activity was detected in membranes of Acetobacter suboxydans (now G. oxydans) KLUYVER-DE LEEUW (Rapin et al., 1967). Oxidation of myo-inositol was determined by measuring oxygen consumption, and, under certain conditions, $\mathrm{Mg}^{2+}$ ions had a positive effect on activity.
Subsequently, the partial purification of a membranebound myo-inositol dehydrogenase from $G$. oxydans NCIB 621 (ATCC 621) was described (Criddle et al., 1974, 1977). In these experiments, myo-inositol dehydrogenase activity was measured in a dye-linked system, indicating the involvement of a flavin or quinone cofactor. The highest myo-inositol dehydrogenase activity in membrane preparations of strain NCIB 621 was obtained in sodium phosphate buffer at $\mathrm{pH} 6.2$, whereas the $\mathrm{pH}$ optimum of the quinoprotein inositol dehydrogenase described in our study is in the alkaline range ( $\mathrm{pH} \mathrm{8.75).} \mathrm{However,} \mathrm{this}$ difference could be due to the different assay conditions used; the assay of Criddle and co-workers also contained DCPIP as the electron acceptor, but lacked PMS as a mediator. In our experiments, omitting PMS resulted in a general drop of myo-inositol dehydrogenase activity; however, similar to the findings of Criddle and co-workers, activity without PMS was higher at $\mathrm{pH} 6$ than at $\mathrm{pH} 8.75$ (data not shown). The $K_{\mathrm{m}}$ value of $60 \mu \mathrm{M}$ determined for the myo-inositol dehydrogenase of strain NCIB 621 (Criddle et al., 1977) is significantly lower than the $\mathrm{K}_{\mathrm{m}}$ value of $5 \mathrm{mM}$ obtained in our study. In strain NCIB 621, solubilization of membrane-bound myo-inositol dehydrogenase was achieved with sodium deoxycholate, which was subsequently removed by gel chromatography (Criddle et al., 1974). This information might be helpful for future attempts to purify quinoprotein inositol dehydrogenase from G. oxydans ATCC $621 \mathrm{H}$.

Whereas information on membrane-bound inositol dehydrogenases is scarce, soluble NAD-dependent myo-inositol dehydrogenases and their genes have been characterized in several species including Bacillus subtilis (Ramaley et al., 1979; Fujita et al., 1991), Klebsiella pneumoniae (Berman \& Magasanik, 1966) and Sinorhizobium meliloti (Galbraith et al., 1998). myo-Inositol is a common compound in soil and plants that can be used for growth by these bacteria. The genome of G. oxydans ATCC $621 \mathrm{H}$ encodes proteins with similarity to NAD-dependent myo-inositol dehydrogenases and additional enzymes involved in cytoplasmic myoinositol metabolism. Thus, in G. oxydans, oxidation of inositol might occur via both a cytoplasmic NAD-dependent and a membrane-bound PQQ-dependent dehydrogenase, as found for several other substrates (Matsushita et al., 1994). However, as shown with mutant DW1 lacking the membrane-bound inositol dehydrogenase, the cytoplasmic inositol dehydrogenase cannot substitute for the function of the membrane-bound enzyme, i.e. provide enough energy for growth. Nonetheless, for unknown reasons, we found that myo-inositol is a rather poor growth substrate also for the wild-type under the conditions used.

As indicated by the lack of the respective activities in mutant DW1, quinoprotein inositol dehydrogenase also oxidized allo- and muco-inositol. The reaction products of quinoprotein inositol dehydrogenase are currently unknown; however, myo-inositol is probably oxidized to 2-keto-myoinositol (myo-inosose-2) as reported for the soluble 
myo-inositol dehydrogenases (e.g. Ramaley et al., 1979) and the membrane-bound myo-inositol dehydrogenase described by Criddle et al. (1974).

Inositol dehydrogenases have been shown to participate in biotechnologically relevant processes; for example, they are involved in the synthesis of aminoglycoside antibiotics (Walker, 1995) and of the drug candidate D-chiro-inositol for treatment of type 2 diabetes and polycystic ovary syndrome (Yoshida et al., 2006). Furthermore, myo-inositol dehydrogenases can be used in enzymic assays for diagnosis of diabetes in its early stages (Yamakoshi et al., 2003). Further characterization of the membrane-bound quinoprotein inositol dehydrogenase, e.g. after purification of the protein, will elucidate its potential for future biotechnical applications.

\section{ACKNOWLEDGEMENTS}

We thank Irmgard Maue-Mohn for technical assistance; Viola Khodaverdi and Lorenz Adrian for helpful discussions; Anke Becker, Universität Bielefeld, for the gift of plasmid pKmobGII; and Armin Ehrenreich and Marc Hoffmeister, Georg-August-University Göttingen, for helpful information on transcription of dehydrogenases in G. oxydans.

This project was carried out within the framework of the Competence Network Göttingen 'Genome research on bacteria' (GenoMik) financed by the German Federal Ministry of Education and Research (BMBF).

\section{REFERENCES}

Adachi, O., Fujii, Y., Ghaly, M. F., Toyama, H., Shinagawa, E. \& Matsushita, K. (2001). Membrane-bound quinoprotein D-arabitol dehydrogenase of Gluconobacter suboxydans IFO 3257: a versatile enzyme for the oxidative fermentation of various ketoses. Biosci Biotechnol Biochem 65, 2755-2762.

Ameyama, M., Shinagawa, E., Matsushita, K. \& Adachi, O. (1981). D-Glucose dehydrogenase of Gluconobacter suboxydans: solubilization, purification and characterization. Agric Biol Chem 45, 851-861.

Ausubel, F. A., Brent, R., Kingston, R. E., Moore, D. D. J. G., Seidman, J. G., Smith, J. A. \& Struhl, K. (2002). Current Protocols in Molecular Biology. New York: Wiley.

Berman, T. \& Magasanik, B. (1966). The pathway of myo-inositol degradation in Aerobacter aerogenes - dehydrogenation and dehydration. J Biol Chem 241, 800-806.

Boyer, H. W. \& Roulland-Dussoix, D. (1969). A complementation analysis of the restriction and modification of DNA in Escherichia coli. J Mol Biol 41, 459-472.

Bremus, C., Herrmann, U., Bringer-Meyer, S. \& Sahm, H. (2006). The use of microorganisms in L-ascorbic acid production. J Biotechnol 124, 196-205.

Cozier, G. E. \& Anthony, C. (1995). Structure of the quinoprotein glucose dehydrogenase of Escherichia coli modelled on that of methanol dehydrogenase from Methylobacterium extorquens. J Biochem 312, 679-685.

Cozier, G. E., Salleh, R. A. \& Anthony, C. (1999). Characterization of the membrane quinoprotein glucose dehydrogenase from Escherichia coli and characterization of a site-directed mutant in which histidine262 has been changed to tyrosine. J Biochem 340, 639-647.
Criddle, W. J., Fry, J. C. \& Keaney, M. M. (1974). myo-Inosito dehydrogenase(s) from Acetomonas oxydans, optimization of conditions for solubilization of membrane-bound enzyme. Biochem J 137, 449-452.

Criddle, W. J., Fry, J. C., Keaney, M. M., Lucas, C. M. \& Tovey, J. A. (1977). myo-Inositol dehydrogenase(s) from Acetomonas oxydans. Mol Cell Biochem 16, 3-6.

Figurski, D. H. \& Helinski, D. R. (1979). Replication of an origincontaining derivative of plasmid RK2 dependent on a plasmid function provided in trans. Proc Natl Acad Sci U S A 76, 1648-1652.

Fujita, Y., Shindo, K., Miwa, Y. \& Yoshida, K. (1991). Bacillus subtilis inositol dehydrogenase-encoding gene $(i d h)$ : sequence and expression in Escherichia coli. Gene 108, 121-125.

Galbraith, M. P., Feng, S. F., Borneman, J., Triplett, E. W., de Bruijn, F. J. \& Rossbach, S. (1998). A functional myo-inositol catabolism pathway is essential for rhizopine utilization by Sinorhizobium meliloti. Microbiology 144, 2915-2924.

Gillis, M. \& de Ley, J. (1980). Intra- and intergeneric similarities of the ribosomal ribonucleic acid cistrons of Acetobacter and Gluconobacter. Int J Syst Bacteriol 30, 7-27.

Goodwin, P. M. \& Anthony, C. (1998). The biochemistry, physiology and genetics of PQQ and PQQ-containing enzymes. Adv Microb Physiol 40, 1-80.

Hanahan, D. (1983). Studies on transformation of Escherichia coli with plasmids. J Mol Biol 166, 557-580.

Hölscher, T. \& Görisch, H. (2006). Knockout and overexpression of pyrroloquinoline quinone biosynthetic genes in Gluconobacter oxydans $621 \mathrm{H}$. J Bacteriol 188, 7668-7676.

Katzen, F., Becker, A., lelmini, M. V., Oddo, C. G. \& lelpi, L. (1999). New mobilizable vectors suitable for gene replacement in gramnegative bacteria and their use in mapping of the $3^{\prime}$ end of the Xanthomonas campestris pv. campestris gum operon. Appl Environ Microbiol 65, 278-282.

Kovach, M. E., Elzer, P. H., Hill, D. S., Robertson, G. T., Farris, M. A., Roop, R. M., II \& Peterson, K. M. (1995). Four new derivatives of the broad-host-range cloning vector pBBR1MCS, carrying different antibiotic-resistance cassettes. Gene 166, 175-176.

Matsushita, K., Toyama, H. \& Adachi, O. (1994). Respiratory chains and bioenergetics of acetic acid bacteria. Adv Microb Physiol 36, 247-301.

Matsushita, K., Fujii, Y., Ano, Y., Toyama, H., Shinjoh, M., Tomiyama, N., Miyazaki, T., Sugisawa, T., Hoshino, T. \& Adachi, O. (2003). 5-Keto-D-gluconate production is catalyzed by a quinoprotein glycerol dehydrogenase, major polyol dehydrogenase, in Gluconobacter species. Appl Environ Microbiol 69, 1959-1966.

Mutzel, A. \& Görisch, H. (1991). Quinoprotein ethanol dehydrogenase: preparation of the apo-form and reconstitution with pyrroloquinoline quinone and $\mathrm{Ca}^{2+}$ or $\mathrm{Sr}^{2+}$ ions. Agric Biol Chem 55, 1721-1726.

Prust, C., Hoffmeister, M., Liesegang, H., Wiezer, A., Fricke, W. F., Ehrenreich, A., Gottschalk, G. \& Deppenmeier, U. (2005). Complete genome sequence of the acetic acid bacterium Gluconobacter oxydans. Nat Biotechnol 23, 195-200.

Ramaley, R., Fujita, Y. \& Freese, E. (1979). Purification and properties of Bacillus subtilis inositol dehydrogenase. J Biol Chem 254, 7684-7690.

Rapin, A., Haenni, A. L. \& Posternak, T. (1967). Recherches sur la biochimie des cyclitols. X. Sur les cyclitol-déshydrogénases d'Acetobacter suboxydans I. Helv Chim Acta 50, 1801-1810.

Sambrook, J., Fritsch, E. F. \& Maniatis, T. (1989). Molecular Cloning: a Laboratory Manual, 2nd edn. Cold Spring Harbor, NY: Cold Spring Harbor Laboratory. 
Toyama, H., Mathews, F. S., Adachi, O. \& Matsushita, K. (2004). Quinohemoprotein alcohol dehydrogenases: structure, function, and physiology. Arch Biochem Biophys 428, 10-21.

Vangnai, A. S., Toyama, H., De-eknamkul, W., Yoshihara, N., Adachi, O. \& Matsushita, K. (2004). Quinate oxidation in Gluconobacter oxydans IFO3244: purification and characterization of quinoprotein quinate dehydrogenase. FEMS Microbiol Lett 241, 157-162.

Walker, J. B. (1995). Enzymatic synthesis of aminocyclitol moieties of aminoglycoside antibiotics from inositol by Streptomyces spp. Detection of glutamine-aminocyclitol aminotransferase and diaminocyclitol aminotransferase activities in a spectinomycin producer. J Bacteriol 177, 818-822.

Yamada, M., Sumi, K., Matsushita, K., Adachi, O. \& Yamada, Y. (1993). Topological analysis of quinoprotein glucose dehydrogenase in Escherichia coli and its ubiquinone-binding site. J Biol Chem 268, 12812-12817.

Yamakoshi, M., Takahashi, M., Kouzuma, T., Imamura, S., Tsuboi, I., Kawazu, S., Yamagata, F., Tominaga, M. \& Noritake, M. (2003). Determination of urinary myo-inositol concentration by an improved enzymatic cycling method using myo-inositol dehydrogenase from Flavobacterium sp. Clin Chim Acta 328, 163-171.

Yoshida, K., Yamaguchi, M., Morinaga, T., Ikeuchi, M., Kinehara, M. \& Ashida, H. (2006). Genetic modification of Bacillus subtilis for production of D-chiro-inositol, an investigational drug candidate for treatment of type 2 diabetes and polycystic ovary syndrome. Appl Environ Microbiol 72, 1310-1315.

Edited by: R. G. Sawers 